\title{
Procedural justice effects on self-esteem under certainty versus uncertainty emotions
}

\author{
David De Cremer · Alain Van Hiel
}

Published online: 8 April 2008

(C) The Author(s) 2008

\begin{abstract}
Building upon the idea that procedural justice effects are more pronounced when uncertainty is high, we proposed that recall of an uncertainty-eliciting emotion (fear) will render people more responsive to variations in procedural justice than will recall of a certainty-eliciting emotion (disgust). Results from Study $1,(n=79$ undergraduate students) confirmed that a fair procedure (voice condition) enhanced self-esteem relative to an unfair procedure (no voice condition) to a greater extent when people recalled fear than when they recalled disgust. Results from Study 2 ( $n=147$ undergraduate students) also showed that a fair, relative to an unfair, procedure enhanced self-esteem more strongly when recalling the emotion of fear rather than disgust, but only when these emotions were recalled from a self-immersed than a self-distanced perspective. These findings confirm that discrete emotions that orient people to interpret situations in uncertain versus certain ways are important antecedents of procedural justice effects.
\end{abstract}

Keywords Procedural justice - Uncertainty ·

Discrete emotions · Self-esteem $\cdot$ Certainty appraisals

The issue of social justice constitutes a salient concern within most of our social interactions (Miller 2001). People

D. De Cremer $(\square)$

Department of Social Psychology, Center of Justice and Social Decision Making (JuST), Tilburg University, P.O. Box 90153, 5000 LE Tilburg, The Netherlands

e-mail: d.decremer@uvt.nl

URL: www.centerofjust.com

A. Van Hiel

Department of Developmental, Personality, and Social

Psychology, Ghent University, Ghent, Belgium have been found to evaluate the justice of what they receive, but an often neglected and maybe even more pervasive concern that people may have is how they are treated in their interactions with the dispensing authorities (see Lind and Tyler 1988). In other words, people are often concerned about the fairness of the procedures used during the decision making process, and this is referred to as procedural justice (Tyler 1988). Over the years, an impressive body of research has demonstrated that procedural fairness (e.g. being allowed to voice one's opinions; Folger 1977) has strong motivational implications, particularly because the enactment of fair versus unfair procedures influences people's self-esteem (for a recent review, see De Cremer and Tyler 2005).

Self-esteem refers to the evaluation of one's own social worth and value and therefore, by definition, is a subjective judgment that is influenced by social events indicating social evaluations and approvals (i.e. sociometer theory, Leary and Baumeister 2000; see also Deci and Ryan 2000). The literature suggests that the enactment of fair procedures represents one such important social event. In other words, procedural justice communicates respect and acceptance towards people and it is assumed that these elements influence the motivational underpinnings of people's self and, therefore, their self-esteem reports (e.g. De Cremer and Sedikides 2005, 2008; Koper et al. 1993; Tyler et al. 1996). These social processes are consistent with a symbolic interactionism perspective in the sense that interpersonal appraisals (e.g. fair procedures) reflect on, and can change, one's self-image (Tice and Wallace 2003).

In a recent review of the justice literature, Brockner et al. (2001) suggested that procedural justice research should adopt the perspective to identify psychological conditions under which procedural justice effects have more versus less impact. Recent experimental research 
indeed seems to have adopted this "moderator" approach to understand when the enactment of fair procedures affects people's responses such as self-esteem most strongly. For example, studies have shown that procedural fairness matters less when decisions are unimportant to participants (Van den Bos and Spruyt 2002), when reference points are distant rather than close (Van den Bos and Van Prooijen 2001), when other information like the trustworthiness of the enacting authority and outcome fairness is available (Van den Bos et al. 1998), when group identification is high (e.g. De Cremer and Van Vugt 2002), and when individuals display a strong need to belong (e.g. De Cremer and Blader 2006).

An important conclusion emerging from this recent line of experimental research is therefore that the effect of procedural justice largely depends on how people interpret information about the procedure. Importantly, however, most of the moderating variables that have been examined in prior studies are cognitive or motivational in nature. In other words, in these experiments, the specific motivational or cognitive state that people are put in determines how procedural justice is interpreted, consequently affecting their reactions. In the present research we propose that procedural justice research to date has not paid appropriate attention to the role of affective states in shaping people's interpretation and experience of procedural justice. Specifically, we argue that considering the moderating effect of specific emotions can contribute to understanding why and when people are motivated to attend to procedural justice, and thus when procedural justice will have more or less influence on self-esteem.

\section{What about the role of affective states?}

To our knowledge, very little research to date has focused on how affective states moderate procedural justice effects. In fact, it is only recently that procedural justice researchers have begun to empirically address this question (see De Cremer 2007, for an overview). Indeed, the only published research that we are aware of it by Van den Bos (2003), who focused on the moderating effect of one specific affective state, that is, mood. Van den Bos applied the idea that mood substantially colors judgmental responses toward a wide array of social events (see Bless 2001; Forgas 2001, 2002; Isen 1999, 2000; Martin et al. 1997; Martin and Clore 2001) to the specific issue of fairness. This affect-as-information approach holds that in the case of a positive mood procedures are evaluated positively and in the case of a negative mood procedures are evaluated negatively (cf. Cacioppo et al. 1999). Van den Bos (2003) indeed showed this to be the case, but particularly so when individuals were uncertain about the fairness of the procedure.
The findings of Van den Bos are important because they support the ideas that (a) justice is in the eye of the beholder and thus subject to people's subjective and affective experiences (see also Barclay et al. 2005; De Cremer 2007), and (b) mood impacts on fairness judgments under specific circumstances (i.e. when uncertainty about fairness information is high). However, it should be noted that applying this affect-as-information approach (as Van den Bos did) mainly shows that the valence of affective states (i.e. positive versus negative mood) influences people's responses, under specific circumstances, but it does not directly focus on why these affective states may evoke different interpretations and thus different effects of procedural justice on people's responses such as self-esteem. We therefore argue that it is important when examining the role of affect in explaining justice effects (i.e. using affective states as moderators of procedural fairness effects) to move beyond simply examining the impact of positive versus negative affective states. More precisely, we also need to explore what kind of interpretations are elicited by specific affective states, consequently affecting whether procedural fairness has more or less impact on people's self-evaluations. For that reason, we believe it is necessary to distinguish between mood and emotions.

Emotions are different from mood in that they are discrete, relatively intense, and short-lived, and are elicited by specific events or persons (Frijda 1993; Russell and Feldman Barrett 1999). As such, using emotions as a moderating variable allows one to examine the influence of affective states carrying the same valence (something that is not possible when manipulating mood). Indeed, research on discrete emotions shows that emotions of the same valence (e.g. fear and disgust; Tiedens and Linton 2001) reveal quite different effects on how situations are interpreted and how these social situations and events consequently impact upon people's responses (De Steno et al. 2000; Lerner and Keltner 2000; Rucker and Petty 2004). For example, research of Lerner et al. (2004) showed that inducing disgust reduced choice prices of an object (i.e. endowment effect) whereas sadness increased choice prices (i.e. reversed endowment effect). Thus, specific emotions with the same valence may lead people to interpret similar social information differently, and this, in turn, may lead to different responses.

Therefore, in line with Lerner et al. (2004), we argue that emotions often elicit interpretations or specific appraisals that form "an implicit lens for interpreting subsequent situations” (p. 337). Appraisal theory (Lazarus 1991; Roseman 1984; Scherer 1988; Smith and Ellsworth 1985) indeed suggests that emotions differ not only in terms of positive-negative valence, but also at the level of appraisal. Appraisals refer to how people evaluate and interpret circumstances and events. In their appraisal- 
tendency theory, Lerner and Keltner (2000) further assert that appraisals not only influence people's reactions in the situations that elicit one or another discrete emotion but also persist beyond these situations (see Lerner et al. 2004, for empirical evidence).

Smith and Ellsworth (1985) identified several appraisal dimensions, including (un)certainty, control, and responsibility. Particularly relevant to understanding the effect of a discrete emotion on the influence of procedural justice on people's self-esteem is the appraisal of (un)certainty. Why? Recently, Van den Bos and Lind (2002) proposed that procedural justice exerts particularly strong influences under conditions of uncertainty. Their uncertainty management model holds that people seek information about procedural justice to reduce uncertainty, and thus predicts a positive relationship between the degree of uncertainty that people experience and their use of procedural justice information. This line of reasoning is consistent with the idea that, in our social world, the belief and affirmation that one will be treated fairly by means of fair procedures signals to people that society is stable and ordered (Lerner and Miller 1978; Miller 2001).

Following this motivational model, we expected that discrete emotions that elicit uncertainty appraisals is more likely to promote procedural justice effects on self-esteem than emotions that do not elicit uncertainty. Moreover, examining the moderating influence of uncertainty-related emotions is also important since prior research generated by the uncertainty management model examined only cognitive (e.g. Van den Bos 2001) or motivational (e.g. De Cremer and Sedikides 2005) variables affecting uncertainty. Therefore, one cannot be sure whether uncertainty evaluations based on emotions reveal similar effects. Indeed, as Van den Bos (2001, p. 940) notes, "all uncertainties are not the same and cannot be expected to have the same effects."

Which emotions elicit (un)certainty appraisals? In several studies, Tiedens and Linton (2001) demonstrated that, for example, the emotions of fear and disgust have different effects because fear was associated with uncertainty and disgust with certainty. In other words, when people feel fearful or are reminded of the emotions of fear, uncertainty was more prominent in their minds than in the case of disgust. Extrapolating from these findings to the present context, it may then well be the case that the emotion of fear (as a proxy of uncertainty) will make people more reactive toward procedural justice information than the emotion of disgust (as a proxy of certainty).

The present research

In the present research, we examine the following predictions. First, building on the finding of prior research that procedural justice has a positive effect on people's self- esteem (e.g. Koper et al. 1993), we expect a main effect of procedural justice to be such that voice will reveal higher self-esteem than no voice (Hypothesis 1). Further, in line with the idea that uncertainty should moderate procedural justice effects (Van den Bos and Lind 2002), we expect that specific emotions acting as a proxy of certainty versus uncertainty will moderate the expected main effect of procedural justice (Hypothesis 2). More precisely, we predict a two-way interaction in such a way that the effect of procedural justice will be stronger when the emotion of fear is made accessible relative to the emotion of disgust, because fear can be considered to represent an uncertainty state, whereas disgust represents a certainty state.

Procedural justice will be manipulated by using the manipulation of voice (Folger 1977; Lind et al. 1990; Van den Bos 1999). Voice refers to a situation in which participants may or may not be allowed to provide input (e.g. opinion) to the decision making process. Having voice is associated with high perceptions of fairness in procedures (McFarlin and Sweeney 1996) and is the most commonly used operationalization of procedural justice in the literature (Van den Bos 1999).

\section{Experiment 1}

\section{Method}

\section{Participants and design}

Seventy-nine undergraduate students (54 females and 25 males, average age $=19.94$ years, $S D=1.86$ ) participated voluntarily in exchange for course credits. They were randomly assigned to a 2 (Emotion: Disgust versus fear) $\times 2$ (Procedural justice: Voice versus no voice) between-subjects factorial design.

\section{Experimental procedure}

Upon arrival in the laboratory, participants were placed in a separate experimental cubicle containing a table, a chair, a pen, and a booklet including all the experimental materials. We told participants to open the booklet and read the experimental instructions carefully.

At the first page of the booklet we explained to participants that some researchers at the department were interested in autobiographical memories about emotional events and that therefore they would first participate in a study about memories that was unrelated to the next study. This first study actually constituted the emotion manipulation and was adapted from Strack et al. (1985) and modeled after Tiedens and Linton (2001). Following Tiedens and Linton (2001), we used the emotions of fear and 
disgust to induce uncertainty and certainty appraisals, respectively. Participants in the disgust condition were asked to remember and vividly recall an event that made them feel disgusted. In the fear condition, participants were asked to recall an event that made them feel afraid. To test our assumption that the emotions of disgust versus fear acted as proxies of certainty versus uncertainty, respectively, we then asked participants the following question, "how well could you predict what would happen next when you felt disgusted/afraid" (taken from Smith and Ellsworth 1985; see also Tiedens and Linton 2001). Participants responded to this questionnaire on an 11-point scale $(1=$ not at all, $11=$ very much so $)$.

After participants finished the 'first study', they were told that they would participate together with other students in a second study. In this study, they would engage in a brainstorming session with other students during which they would discuss topics that are of importance to the university and its students. Then, a list of possible topics was introduced by the researcher: (1) Binding study advice (whether students have to be evaluated after their first year to see whether or not they can proceed), (2) Life on campus (whether their university campus should be made more attractive, and how), and (3) The lack of student rooms in their city. Participants were told that only one topic could be discussed. They were then informed about the procedure that would be used to select the discussion topic. This constituted the procedural justice manipulation. Half of the participants read a note that they would be given the opportunity to voice their opinion with respect to which topic to choose. Then, they were asked to write down which topic that they wanted to select and why (voice condition). The other half of the participants read that they would not be given the opportunity to voice their opinion with respect to which topic to choose (no voice condition).

Then, the dependent measures of experiment 1 were solicited. First, participants were asked to write down which emotion they had. Participants responded to the remaining questions on a 7 -point scale $(1=$ not at all, $7=$ very much so). To check the procedural justice manipulation, participants rated the degree to which opinion was considered. Self-esteem was assessed by asking participants to rate the degree to which they evaluated themselves as "respected", "valued", and "less than others" (reversed). These items were taken from prior justice research (De Cremer and Sedikides 2008; De Cremer and Tyler 2005) and from scales assessing relational and social dimensions of self-esteem (Leary et al. 2001; McFarland and Ross 1982; Heatherton and Polivy 1991; Routledge et al. 2007, Nostalgia proneness and nostalgia functions, unpublished). They were combined to produce an average self-esteem score (Cronbach's $\alpha=.82$ ). Finally, participants were debriefed and thanked.
Results

\section{Manipulation checks}

Two judges coded whether participants indeed described the emotion of fear versus disgust as prescribed by their experimental condition. The judges agreed in coding the emotions as shown in the high inter-rater agreement, Cohen's Kappa $=.90$. Moreover, all participants described the emotion that was prescribed for by their experimental condition. A 2 (Emotion) $\times 2$ (Procedural justice) ANOVA on the certainty-uncertainty appraisal question yielded only a significant main effect of Emotion, $F(1$, $75)=12.40, p<.001, \eta^{2}=.14$. Participants judged the situation to be more predictable in the disgust than in the fear condition $(M \mathrm{~s}=5.92$ vs. $3.77, S D \mathrm{~s}=2.91$ and 2.49 , respectively). A $2 \times 2$ ANOVA on participants' rating of the degree to which their opinion was considered revealed only a significant effect of Procedural justice, $F(1$, $75)=75.09, p<.001, \eta^{2}=.50$. Participants felt they were given more consideration in the voice relative to the no voice condition $(M \mathrm{~s}=5.83$ vs. $2.83, S D \mathrm{~s}=0.77$ and 2.07 , respectively).

\section{Self-esteem}

A $2 \times 2$ ANOVA on the average self-esteem score yielded, in line with Hypothesis 1 that procedural justice will have a positive influence on self-esteem, a significant main effect of procedural justice, $F(1,75)=81.80, p<.001$, $\eta^{2}=.52$ : Participants in the voice condition indeed reported higher self-esteem than those in the no voice condition $(M \mathrm{~s}=5.69$ vs. $3.70, S D \mathrm{~s}=0.79$ and 1.24 , respectively). Interestingly, there was also a significant main effect of emotion, $F(1,75)=7.40, p<.01, \eta^{2}=.09$ : Participants in the disgust condition reported higher self-esteem than those in the fear condition $(M \mathrm{~s}=5.00$ vs. 4.40, $S D \mathrm{~s}=1.24$ and 1.56 , respectively).

Finally, there was a significant effect for the interaction between emotion and procedural justice, $F(1,75)=3.96$, $p=.05, \eta^{2}=.05$ (see Table 1). As expected, analyses of the effect of procedural justice at each level of the

Table 1 Means and standard deviations of self-esteem as a function of emotion and procedural justice

\begin{tabular}{llll}
\hline Dependent variable & Emotion & & \\
\cline { 2 - 4 } & Procedural justice & Fear & Disgust \\
\hline Self-esteem & Voice & $5.61^{\mathrm{a}}(0.84)$ & $5.77^{\mathrm{a}}(0.75)$ \\
& No voice & $3.18^{\mathrm{c}}(1.08)$ & $4.22^{\mathrm{b}}(1.19)$ \\
\hline
\end{tabular}

Note: A higher score indicates higher self-esteem. Standard deviations are given in parentheses. Means with a different subscript differ at $p<.05$ 
independent variable emotion showed that procedural justice revealed a stronger significant effect (see effect sizes) among those in the fear (uncertainty) condition, $F(1$, $75)=61.85, p<.001, \eta^{2}=.45$, than those in the disgust (certainty) condition, $F(1,75)=24.50, p<.001, \eta^{2}=.24$. In line with Hypothesis 2, self-esteem was higher in the voice than in the no voice condition, and this effect was more pronounced when the emotion of fear rather than disgust was recalled. Additional analyses of the effect of emotion in each condition of procedural justice also showed that the effect of emotion was significant in the no voice condition, $F(1,75)=10.68, p<.005$, but not in the voice condition, $F(1,75)=.28, p<.61$. In other words, in the no voice condition, self-esteem was higher in the condition of disgust than in the condition of fear. We will return to this finding in the general discussion.

\section{Experiment 2}

The findings of Experiment 1 indicated that the procedural justice manipulation influenced self-esteem more strongly when people recalled the emotion of fear, which induces higher appraisals of uncertainty, than when they recalled disgust. To the best of our knowledge, this demonstration of the moderating effect of discrete emotions such as fear and disgust is the first of its kind. Moreover, this significant effect supports our proposal that integrating insights from the appraisal and procedural justice literatures can contribute to understanding the role of uncertainty in procedural justice effects.

In Experiment 2 participants' self-esteem again served as the dependent measure. The main objective was to examine whether the moderating effect of emotions will be particularly marked when the emotion is mentally experienced in a self-relevant manner. This proposal rests on two kinds of considerations. First, De Cremer and Sedikides (2005) showed that uncertainty related to the self was associated with strong procedural justice effects. Second, recent evidence shows that justice effects become more pronounced and stronger when people focus on the self (see Skitka 2003). We thus predicted that fear will reveal stronger procedural justice effects than disgust, but particularly when these emotions are recalled under conditions of attention to the self. Conversely, we predicted that this interaction effect between uncertainty (i.e. fear) versus certainty related (i.e. disgust) emotions and procedural justice will not emerge when people do not focus on the self.

The manipulation of self-focus relied on recent research demonstrating that emotional experiences can be recalled in ways that reflect different self-immersed versus selfdistanced perspectives (see Kross et al. 2005). A selfimmersed perspective makes people focus on the specific features of the recalled emotion and relive the situation (McIsaac and Eich 2004). In contrast, a self-distanced perspective puts people more in a reflective mode in which they process the emotion more from a third-person perspective (Robinson and Swanson 1993).

To summarize, in addition to a main effect of procedural justice (Hypothesis 1) and a two-way interaction between procedural justice and emotion (Hypothesis 2), as examined in Experiment 1, we anticipated a three-way interaction between procedural justice, emotion and type of self-perspective (Hypothesis 3). Specifically, we predicted that the moderating influence of fear relative to disgust on the positive effect of voice procedures on self-esteem would be stronger when participants recalled the emotion from a self-immersed relative to a self-distanced perspective.

Method

\section{Participants and design}

Participants were 147 undergraduate students (66 men and 81 women; average age $=20.80$ years, $S D=2.97$ ) who participated voluntarily and were each paid 7 Euros. They were randomly assigned to a 2 (Perspective: Self-immersed versus self-distanced) $\times 2$ (Emotion: Disgust versus fear) $\times 2$ (Procedural justice: Voice versus no voice) between-subjects factorial design.

\section{Procedure}

Upon arrival in the laboratory, participants were directed to a cubicle containing a table, chair, pen, and computer. All information was communicated via the computer. As in Experiment 1, participants were first told that they would participate in a first (unrelated) study and were asked to recall a situation of fear relative to disgust. The type of self-perspective manipulation was then introduced (taken from Kross et al. 2005). Instructions for the self-immersed perspective condition were " "go back to the situation described and relive the situation as if it were happening to you all over again ...." Instructions for the self-distanced perspective were " take a few steps back and move away from your experience ... watch the situation in such a way as if it were happening all over again to the distant you." As in Experiment 1, (un)certainty was assessed by asking participants to rate how well they could predict what would happen next when they felt disgusted/afraid". In addition, two items assessed whether the autobiographical memory task elicited the emotion that was described: "To what extent do you feel disgust at the moment", and "to what extent do you feel fear at the moment."

Participants then participated in the "second" study. Procedures, which included the procedural justice 
manipulation, were as described for Experiment 1. Thereafter, the dependent measures of experiment 2 were solicited. All questions were answered on a 7-point scale $(1=$ not at all, $7=$ very much so $)$, ranging from not at all (1) to very much so (7). The validity of the procedural justice manipulation and the emotion manipulation were assessed as described for Experiment 1. In addition, because in Experiment 1 we did not check whether our voice manipulation indeed elicited a sense of fairness, in Experiment 2, participants rated how "fairly" and "justly" they felt treated $(r=.89, p<.001)$. Self-esteem was then assessed by asking participants to what extent they evaluated themselves as someone "valued", and "proud of him or herself" (taken from De Cremer and Sedikides 2008; Tyler et al. 1996; $r=.61, p<.001)$. Finally, participants were debriefed and thanked.

\section{Results}

\section{Manipulation checks}

Two judges coded whether participants indeed described the emotion of fear versus disgust as prescribed by their experimental condition. The judges agreed in coding the emotions as shown in the high inter-rater agreement, Cohen's Kappa $=.86$. Moreover, all participants described the emotion that was prescribed for by their experimental condition. Further, two judges also coded whether participants adopted a self-immersed perspective or a selfdistanced perspective as prescribed by their experimental condition. This time the judges also showed high agreement as shown in the high inter-rater agreement, Cohen's Карра $=.85$.

A 2 (perspective) $\times 2$ (emotion) $\times 2$ (procedural justice) ANOVA on the disgust question yielded only a significant main effect of emotion, $F(1,139)=12.60$, $p<.001, \eta^{2}=.08$ : Participants in the disgust condition felt more disgusted than those in the fear condition $(M \mathrm{~s}=6.33$ vs. $1.89, S D \mathrm{~s}=1.09$ and 1.45 , respectively). A $2 \times 2 \times 2$ ANOVA on the fear question yielded only a significant main effect of emotion, $F(1,139)=108.05$, $p<.001, \eta^{2}=.44$ : Participants in the fear condition felt more fearful than those in the disgust condition ( $M \mathrm{~s}=5.56$ vs. $2.79, S D \mathrm{~s}=1.24$ and 1.86 , respectively). A $2 \times 2 \times 2$ ANOVA on the certainty-uncertainty appraisal revealed only a significant main effect of emotion, $F(1,139)=12.60, p<.001, \eta^{2}=.08$ : Participants in the disgust condition evaluated that they could predict what would happen next much better than among those in the fear condition $(M \mathrm{~s}=5.66$ vs. $3.92, S D \mathrm{~s}=3.27$ and 2.49 , respectively).

A $2 \times 2 \times 2$ ANOVA on the voice manipulation check yielded only a significant main effect of procedural justice,
$F(1,139)=507.91, p<.001, \eta^{2}=.79$ : Participants in the voice condition felt that they were listened to more than those in the no voice condition $(M \mathrm{~s}=5.52$ vs. 1.34 , $S D \mathrm{~s}=1.40$ and 0.75 , respectively). Also, a $2 \times 2 \times 2$ ANOVA on the average fairness score only yielded a significant main effect of procedural justice, $F(1$, $139)=106.90, p<.001, \eta^{2}=.44:$ Participants with a voice felt that they were treated more fairly than those in the no voice condition $(M \mathrm{~s}=4.84$ vs. $2.35, S D \mathrm{~s}=1.47$ and 1.44 , respectively).

\section{Self-esteem}

A $2 \times 2 \times 2$ ANOVA on the average self-esteem score yielded, first of all, and in line with hypothesis 1 , a significant main effect of procedural justice, $F(1,139)=8.40$, $p<.001, \eta^{2}=.06$ : Self-esteem was higher when voice was given relative to no voice $(M \mathrm{~s}=4.54$ vs. $3.81, S D \mathrm{~s}=1.43$ and 1.78, respectively). Again, a significant main effect of emotion was also found, $F(1,139)=9.13, p<.005$, $\eta^{2}=.06$ : Self-esteem was higher when disgust was recalled relative to fear $(M \mathrm{~s}=4.56$ vs. $3.80, S D \mathrm{~s}=1.57$ and 1.65 , respectively). Analyses also revealed a significant interaction between emotion and procedural justice (Hypothesis 2), $F(1,139)=6.96, p<.01, \eta^{2}=.05$, and between perspective and procedural justice, $F(1,139)=3.99, p<.05$, $\eta^{2}=.03$. Most importantly, however, a significant threeway interaction emerged, $F(1,139)=3.78, p=.05$, $\eta^{2}=.03$ (see Table 2).

To analyze this interaction further, we examined the two-way interaction between emotion and procedural justice at each level of the independent variable Perspective. In line with hypothesis 3 that the interaction between emotion and procedural justice (as was found in experiment 1) would be a function of the type of self-perspective, these analyses showed that the interaction between emotion and procedural justice was significant in the self-immersed perspective condition, $F(1,139)=10.42, p<.005$, but not in the self-distanced condition, $F(1,139)<1, p<.63$.

Table 2 Means and standard deviations of self-esteem as a function of perspective, emotion, and procedural justice

\begin{tabular}{llll}
\hline Perspective & Procedural justice & Emotion \\
\cline { 3 - 4 } & & Fear & Disgust \\
\hline Self-immersed & Voice & $4.68^{\mathrm{a}}(1.35)$ & $4.61^{\mathrm{a}}(1.58)$ \\
& No voice & $2.31^{\mathrm{b}}(0.92)$ & $4.53^{\mathrm{a}}(1.78)$ \\
Self-distanced & Voice & $4.32^{\mathrm{a}}(1.35)$ & $4.53^{\mathrm{a}}(1.49)$ \\
& No voice & $3.92^{\mathrm{a}}(1.87)$ & $4.58^{\mathrm{a}}(1.52)$ \\
\hline
\end{tabular}

Note: A higher score indicates higher self-esteem. Standard deviations are given in parentheses. Means with a different subscript differ at $p<.05$ 
Further analyses of the two-way interaction between emotion and procedural justice at the level of the selfimmersed condition showed that the effect of procedural justice was significant when participants recalled the emotion fear, $F(1,139)=21.40, p<.001$, but not when they recalled the emotion of disgust, $F(1,139)<1$, $p<.88$. As expected, in the fear condition, self-esteem was higher when voice was given rather than no voice. Further, the effect of emotion was significant in the no voice condition, $F(1,139)=19.85, p<.001$, but not in the voice condition, $F(1,139)<1, p<.89$. That is, in the no voice condition, self-esteem was higher in the disgust condition than in the fear condition. We will return to this latter finding in the general discussion.

\section{General discussion}

Taken together, the present findings showed that the enactment of fair procedures has a positive effect on selfesteem, but particularly so when the emotion of fear relative to disgust is recalled. This effect of fear versus disgust was particularly pronounced when the emotion was recalled from a self-immersed rather than a self-distanced perspective. In the following paragraphs, we discuss the most important implications.

The first important finding of the present research concerns the observation that discrete emotions moderated the effect of procedural justice on self-esteem. Indeed, procedural justice promoted participants' self-esteem, but particularly when an uncertainty-associated emotion (e.g. fear), relative to a certainty-associated emotion (e.g. disgust), was recalled. This finding supports the idea that discrete emotions can serve as a lens through which people evaluate subsequent social information such as the fairness of decision making procedures (cf. Lerner et al. 2004). One specific type of appraisal that is particularly relevant to procedural justice is uncertainty (Van den Bos and Lind 2002). Therefore, we expected and indeed found that discrete emotions eliciting an uncertainty appraisal (e.g. fear) reinforced procedural justice effects.

A second important finding is that the influence of fear versus disgust on the effects of procedural justice was particularly influential when participants adopted a selfimmersed rather than a self-distanced perspective. Both theoretical and empirical analyses have suggested that particularly uncertainty with respect to the self moderates the effects of fairness of procedures (De Cremer and Sedikides 2005), and that the effects of justice become stronger when self-focus is heightened (Skitka 2003). In addition, recent research (see Kross et al. 2005) has also shown that the type of self-perspective that people adopt influences their reactions to an anger-eliciting interpersonal experience like unfair treatment. Our results are thus supportive of these previous insights as we indeed show that discrete emotions install an interpretative frame of uncertainty which moderates the effect of procedural justice on self-esteem, and particularly so when the emotion is recalled within a self-immersed perspective.

The present data also yielded some other interesting observations. First, across both experiments our emotion manipulation moderated self-esteem in the no voice condition, but not in the voice condition. This effect does not corroborate the widely shared assumption that justice effects should be considered "fair process" effects. That is, in the procedural justice literature scholars typically interpret fairness manipulations in terms of fairness rather than unfairness (see Bies and Tripp 2002). However, evidence is accumulating that people tend to be stronger affected by unfair than by fair events (see Tripp and Bies 2007, for an overview). As a result, it would be more appropriate to talk about the psychology of injustice rather than of justice (De Cremer and Ruiter 2003). Our present findings indeed support the idea of the "unfair process" effect as the impact of recalling an uncertainty-related versus a certainty-related emotion only yielded a significant effect when participants were treated unfairly. In fact, our results showed that self-esteem reports were lowest in the fear/no voice condition.

Another interesting finding relates to the observation that in Experiment 1 procedural justice had a significant effect on self-esteem in the disgust condition, whereas this was not the case in the second experiment (in both the selfimmersed and self-distanced condition). This inconsistent finding raises the question whether our emotion manipulation did more than simply eliciting uncertainty versus certainty appraisals. In response to such a question, it is, first of all, important to note that our results provided convincing evidence that the emotion manipulations of fear and disgust were affecting uncertainty appraisals in the experimental context (see also Tiedens and Linton 2001). Furthermore, it is clear that the pattern of findings is consistent with the prediction of the uncertainty management model that procedural justice effects become stronger in the context of uncertainty. Moreover, many procedural justice studies have shown that not every single moderator variable completely rules out the effect of the voice manipulation on the dependent variable under investigation (as is the case in Experiment 1). This effect found in Experiment 1 is presumably caused by the pervasiveness of the voice effect and its direct impact on the self. Thus, overall, our findings can be interpreted in terms of the affective uncertainty-certainty dimension that we introduced in the present paper. Nevertheless, the finding that voice sometimes revealed an effect on self-esteem when disgust was primed makes clear the necessity for future 
research to delineate more precisely the extent to which the specific emotion of disgust (relative to fear) elicits appraisals that make people responsive to social information such as (un)fair treatment.

To summarize so far, our results should be considered important for the following reasons. First, our findings demonstrate that it is worthwhile to use discrete emotions as moderators of procedural justice effects. The use of discrete emotions allows us to examine the influence of affective states beyond their sheer valence, but, maybe even more importantly, helps us to test in a more direct manner why procedural justice matters to people. Indeed, as evinced by the present experiments, the discrete emotions of fear and disgust elicited specific appraisals that acted as proxies of uncertainty versus certainty, thereby providing further evidence that procedural justice effects are closely linked to the motive of uncertainty (Van den Bos and Lind 2002). Second, research to date only looked at cognitive (Van den Bos 2001; Van den Bos and Miedema 2000) or motivational (De Cremer and Sedikides 2005) uncertainty-related variables, but our findings show that the emotional dimension of uncertainty also plays a role in this process. Third, our research further contributes to the idea that procedural justice rules such as voice affect people's motives and self because they communicate selfrelevant information (De Cremer and Tyler 2005). Indeed, the present effects of procedural justice on self-esteem were particularly pronounced when adopting an immersed self-perspective. Of course, in the present research, we did not include other dependent measures and therefore we have to remain cautious in emphasizing the important role of the self in appraisals and its impact on procedural justice effects. Therefore, future research should examine the role of the self in the interactive effect between procedural justice and discrete emotions and to include other dependent measures like, for example, cooperation and relationships with the group authority and other team members (cf. De Cremer and Tyler 2005).

Finally, both our main findings and prior ones seem to feed into the conclusion that different psychological dimensions are involved in the moderating influence of uncertainty on procedural justice effects. Indeed, cognitive, motivational and emotional components of uncertainty seem able to enhance procedural justice effects and thus an integrative approach seems most warranted when further unraveling the relationship between uncertainty and justice. We hasten to say that this conclusion should not come as a surprise since social psychologists have demonstrated that cognition and affect often interact in predicting human behavior (Forgas 2000) and justice judgments (Van den Bos 2003), and that cognition is often motivated (Kruglanski 1996). We therefore believe that justice effects should not understood solely in terms of cognition, emotion, or motivation, but that all these processes mutually influence each other.

Some possible limitations also need to be outlined. A possible limitation is that the present research only used specific emotions with a negative valence (i.e. fear and disgust) and refrained from using emotions with a positive valence. One may then wonder whether similar effects would have been found if positive emotions with certainty versus uncertainty appraisals were used. This may well be the case as research by Tiedens and Linton (2001) showed that certainty dimension, and not valence, mattered in explaining the effects of specific emotions. Nevertheless, it would be interesting for future research to examine this issue in greater detail.

Another possible limitation is that we did not include a control condition in our experimental designs. Including such a control condition could further clarify the specific effects of our emotion manipulations. However, our primary aim was to investigate whether specific emotions differing in their level of uncertainty appraisal would influence the impact of voice on people's responses in a similar way as found in previous studies using cognitive or motivational operationalizations of uncertainty. While our results were supportive of this 'affective moderating' effect, it would be interesting for future research to investigate whether a baseline condition eliciting no certainty or uncertainty appraisals would reveal weaker procedural justice effects on self-esteem relative to a fear condition and stronger effects relative to a disgust condition.

A final possible limitation is that we only focused on one instance of unfair treatment, that is, voice. We decided to do this because the operationalization of voice has received the greatest attention in the literature and it is the most effective and accepted manipulation of procedural justice. However, Leventhal (1980) identified several procedural justice criteria (e.g. consistency, correctability, ethicality, accuracy), and, in their meta-analysis, Cohen-Charash and Spector (2001) pointed out that "although we have enough data on some aspects ... (e.g. voice), we do not have enough data on other aspects ..., such as correctability and representativeness" (p. 308). Therefore, it would be interesting to see whether the moderating effect of uncertainty-associated versus certainty-associated emotions also emerges when using another procedural justice manipulation.

To conclude, the current investigation establishes (un)certainty-associated emotions as important moderators of responses to variations in procedural justice. Our results showed that if people recall the emotion of fear (relative to disgust), their self-esteem is particularly influenced as a reaction to procedural fairness. Importantly, though, this interactive effect between emotion certainty and procedural justice was a function of the type of self-perspective that 
people adopted. We hope that the present investigation will spark additional forays into the relation between emotions, uncertainty and procedural justice.

Acknowledgements This research was supported by a research grant from the Netherlands Organization for Scientific Research (NWO, Grant No. 016-005.019). The authors thank Lieven Brebels and Jeroen Stouten for their comments on an earlier draft of this paper.

Open Access This article is distributed under the terms of the Creative Commons Attribution Noncommercial License which permits any noncommercial use, distribution, and reproduction in any medium, provided the original author(s) and source are credited.

\section{References}

Barclay, L. J., Skarlicki, D. P., \& Pugh, S. D. (2005). Exploring the role of emotions in injustice perceptions and retaliation. Journal of Applied Psychology, 90, 629-643.

Bies, R. J., \& Tripp, R. M. (2002). Hot flashes, open wounds: Injustice and the tyranny of its emotions. In S. Gilliland, D. Steiner, \& D. Skarlicki (Eds.), Emerging perspectives on managing organizational justice (pp. 203-223). Greenwich, CT: Information Age Publishing.

Bless, H. (2001). The consequences of mood on the processing of social information. In A. Tesser \& N. Schwarz (Eds.), Blackwell handbook of social psychology: Intraindividual processes (pp. 391-412). Oxford: Blackwell.

Brockner, J., Ackerman, G., \& Fairchild, G. (2001). When do elements of procedural fairness make a difference? A classification of moderating differences. In J. Greenberg \& R. Cropanzano (Eds.), Advances in organizational justice (pp. 179-212). Stanford, CA: Stanford University Press.

Cacioppo, J. T., Gardner, W. L., \& Berntson, G. G. (1999). The affect system has parallel and integrative processing components: Form follows function. Journal of Personality and Social Psychology, $76,839-855$.

Cohen-Charash, Y., \& Spector, P. E. (2001). The role of justice in organizations: A meta-analysis. Organizational Behavior and Human Decision Processes, 86, 278-321.

Deci, E. L., \& Ryan, R. M. (2000). The what and why of goal pursuits: Human needs and the self-determination of behavior. Psychological Inquiry, 11, 227-268.

De Cremer, D. (Ed.). (2007). Advances in the psychology of justice and affect. Greenwich, CT: Information Age Publishing.

De Cremer, D., \& Blader, S. (2006). Why do people care about procedural fairness? The importance of belongingness in responding and attending to procedures. European Journal of Social Psychology, 36, 211-228.

De Cremer, D., \& Ruiter, R. A. C. (2003). Emotional reactions toward procedural fairness as a function of negative information. Journal of Social Psychology, 143, 793-795.

De Cremer, D., \& Sedikides, C. (2005). Self-uncertainty and responsiveness to procedural justice. Journal of Experimental Social Psychology, 41, 151-173.

De Cremer, D., \& Sedikides, C. (2008). Reputational implications of procedural fairness for personal and relational self-esteem. Basic and Applied Social Psychology, 30, 1-10.

De Cremer, D., \& Tyler, T. R. (2005). Managing group behavior: The interplay between procedural fairness, sense of self, and cooperative behavior. In M. Zanna (Ed.), Advances in experimental social psychology (Vol. 37, pp. 151-218). New York: Elsevier.

De Cremer, D., \& Van Vugt, M. (2002). Intergroup and intragroup aspects of leadership in social dilemmas: A relational model of cooperation. Journal of Experimental Social Psychology, 38, 126-136.

DeSteno, D., Petty, R. E., Wegener, D. T., \& Rucker, D. D. (2000). Beyond valence in the perception of likelihood: The role of emotion specificity. Journal of Personality and Social Psychology, 78, 397-416.

Folger, R. (1977). Distributive and procedural justice: Combined impact of "voice" and improvement of experienced inequity. Journal of Personality and Social Psychology, 35, 108-119.

Forgas, J. P. (2000). Feeling and thinking: The role of affect and social cognition. Cambridge, UK: Cambridge University Press.

Forgas, J. P. (Ed.). (2001). The Handbook of affect and social cognition. Mahwah, NJ: Lawrence Erlbaum Associates.

Forgas, J. P. (2002). Feeling and doing: Affective influences on interpersonal behavior. Psychological Inquiry, 13, 1-28.

Frijda, N. (1993). Moods, emotion episodes, and emotions. In M. Lewis \& I. M. Haviland (Eds.), Handbook of emotions (pp. 381403). New York: Guilford Press.

Heatherton, T. F., \& Polivy, J. (1991). Development and validation of a scale for measuring self-esteem. Journal of Personality and Social Psychology, 60, 895-910.

Isen, A. M. (1999). Positive affect. In T. Dagleish \& M. Power (Eds.), The handbook of cognition and emotion (pp. 521-539). Sussex, England: Wiley.

Isen, A. M. (2000). Positive affect and decision making. In M. Lewis \& J. Haviland-Jones (Eds.), Handbook of emotions (2nd ed.). New York: Guilford.

Koper, G., van Knippenberg, D., Bouhuijs, F., Vermunt, R., \& Wilke, H. (1993). Procedural fairness and self-esteem. European Journal of Social Psychology, 23, 313-325.

Kross, E., Ayduk, O., \& Mischel, W. (2005). When asking “why” does not hurt: Distinguishing rumination from reflective processing of negative emotions. Psychological Science, 16, 709-715.

Kruglanski, A. W. (1996). Motivated social cognition: Principles of the interface. In E. T. Higgins \& A. W. Kruglanski (Eds.), Social psychology: Handbook of basic principles (pp. 493-520). New York, NY: Guilford Press.

Lazarus, R. S. (1991). Emotion and adaptation. Oxford, UK: Oxford University Press.

Leary, M. R., \& Baumeister, R. F. (2000). The nature and function of self-esteem: Sociometer theory. Advances in Experimental Social Psychology, 32, 1-62.

Leary, M. R., Cottrell, C. A., \& Phillips, M. (2001). Deconfounding the effects of dominance and social acceptance on self-esteem. Journal of Personality and Social Psychology, 81, 898-909.

Lerner, J. S., \& Keltner, D. (2000). Beyond valence: Toward a model of emotion-specific influences on judgment and choice. Cognition and Emotion, 14, 473-493.

Lerner, M. J., \& Miller, D. T. (1978). Just-world research and the attribution process: Looking back and ahead. Psychological Bulletin, 85, 1030-1051.

Lerner, J. S., \& Small, D. A., \& Loewenstein, G. (2004). Heart strings and purse strings: Carryover effects of emotions and economic decisions. Psychological Science, 15, 337-341.

Leventhal, G. S. (1980). What should be done with equity theory? New approaches to the fairness in social relationships. In K. Gergen, M. Greenberg, \& R. Willis (Eds.), Social exchange theory (pp. 27-55). New York: Plenum.

Lind, E. A., Kanfer, R., \& Earley, P. C. (1990). Voice, control, and procedural justice: Instrumental and non-instrumental concerns in fairness judgments. Journal of Personality and Social Psychology, 59, 952-959. 
Lind, E. A., \& Tyler, T. R. (1988). The social psychology of procedural justice. New York: Plenum.

Martin, L., Abend, T., Sedikides, C., \& Green, J. D. (1997). How would I feel if ...? Mood as input to a role fulfillment evaluation process. Journal of Personality and Social Psychology, 73, 242 253

Martin, L., \& Clore, G. L. (Eds.). (2001). Theories of mood and cognition: A user's guidebook (pp. 135-157). Mahwah, NJ: Lawrence Erlbaum Associates, Inc.

McFarland, C., \& Ross, M. (1982). Impact of causal attributions on affective reactions to success and failure. Journal of Personality and Social Psychology, 43, 937-946.

McFarlin, D. B., \& Sweeney, P. D. (1996). Does having a say matter only if you get your way? Instrumental and value expressive effects of employee voice. Basic and Applied Social Psychology, $18,289-303$

McIsaac, H. K., \& Eich, E. (2004). Vantage point in traumatic memory. Psychological Science, 15, 248-253.

Miller, D. T. (2001). Disrespect and the experience of injustice. Annual Review of Psychology, 52, 527-553.

Robinson, J. A., \& Swanson, K. L. (1993). Field and observer modes of remembering. Memory, 1, 169-184.

Roseman, I. J. (1984). Cognitive determinants of emotion: A structural theory. Review of Personality and Social Psychology, $5,11-36$.

Rucker, D. D., \& Petty, R. E. (2004). Emotion specificity and consumer behavior: Anger, sadness, and preference for activity. Motivation and Emotion, 28, 3-21.

Russell, J. A., \& Feldman Barrett, L. F. (1999). Core affect, prototypical emotional episodes, and other things called emotion: Dissecting the elephant. Journal of Personality and Social Psychology, 76, 805-819.

Scherer K. R. (1988). Facets of emotion: Recent research. Hillsdale, $\mathrm{NJ}$ : Erlbaum.

Skitka, L. J. (2003). Of different minds: An accessible identity model of justice reasoning. Personality and Social Psychology Review, 7, 286-297.

Smith, C. A., \& Ellsworth, P. C. (1985). Patterns of cognitive appraisal in emotion. Journal of Personality and Social Psychology, 48, 813-838.

Strack, F., Schwarz, N., \& Gschneidinger, E. (1985). Happiness and reminiscing: The role of time perspective, mood, and mode of thinking. Journal of Personality and Social Psychology, 49, $1460-1469$.

Tice, D. M., \& Wallace, H. M. (2003). The reflected self: Creating yourself as (you think) others see you. In M. R. Leary \& J. P.
Tangney (Eds.), Handbook of self and identity (pp. 91-105). New York: Guilford Press.

Tiedens, L. Z., \& Linton, S. (2001). Judgment under emotional certainty and uncertainty: The effects of specific emotions on information processing. Journal of Personality and Social Psychology, 81, 973-988.

Tripp, T.M., \& Bies, R.J. (2007). Scholarly biases in studying justice and emotion: If we don't ask, we don't see. In D. De Cremer (Ed.), Advances in the psychology of justice and affect (pp. 175190). Charlotte, NC: Information Age Publishing.

Tyler, T. R. (1988). What is procedural justice? Law and Society Review, 22, 301-355.

Tyler, T. R., Degoey, P., \& Smith, H. (1996). Understanding why the justice of group procedures matter: A test of the psychological dynamics of the group-value model. Journal of Personality and Social Psychology, 70, 913-930.

Van den Bos, K. (1999). What are we talking about when we talk about no-voice procedures? On the psychology of the fair outcome effect. Journal of Experimental Social Psychology, 35, 560-577.

Van den Bos, K. (2001). Uncertainty management: The influence of uncertainty salience on reactions to perceived procedural fairness. Journal of Personality and Social psychology, 80, 931941.

Van den Bos, K. (2003). On the subjective quality of social justice: The role of affect as information in the psychology of justice judgments. Journal of Personality and Social Psychology, 85, 482-498.

Van den Bos, K., \& Lind, E. A. (2002). Uncertainty management by means of fairness judgments. In M. P. Zanna (Ed.), Advances in experimental social psychology (Vol. 34, pp. 1-60). San Diego, CA: Academic Press.

Van den Bos, K., \& Miedema, J. (2000). Toward understanding why fairness matters: The influence of mortality salience on reactions to procedural fairness. Journal of Personality and Social Psychology, 79, 355-366.

Van den Bos, K., \& Spruijt, N. (2002). Appropriateness of decisions as a moderator of the psychology of voice. European Journal of Social Psychology, 32, 57-72.

Van den Bos, K., \& Van Prooijen, J.-W. (2001). Referent cognitions theory: The role of closeness of reference points in the psychology of voice. Journal of Personality and Social Psychology, 81, 616-626.

Van den Bos, K., Wilke, H. A. M., \& Lind, E. A. (1998). When do we need procedural fairness? The role of trust in authority. Journal of Personality and Social Psychology, 75, 1449-1458. 